\title{
Regulation of Activin mRNA and Smad2 Phosphorylation by Antidepressant Treatment in the Rat Brain: Effects in Behavioral Models
}

\author{
Antonia L. Dow, David S. Russell, and Ronald S. Duman \\ Laboratory of Molecular Psychiatry, Departments of Psychiatry and Pharmacology, Yale University School of Medicine, New Haven, Connecticut 06508
}

\begin{abstract}
Activin is a member of the transforming growth factor- $\beta$ family that is involved in cell differentiation, hormone secretion, and regulation of neuron survival. The cellular responses to activin are mediated by phosphorylation of a downstream target, Smad2. The current study examines the influence of chronic electroconvulsive seizures (ECSs), as well as chemical antidepressants, on the expression of activin $\beta \mathrm{A}$ and the phosphorylation of Smad2 in the rat hippocampus and frontal cortex. Chronic ECSs $(10 \mathrm{~d})$ resulted in a significant increase in activin $\beta$ A mRNA expression and Smad2 phosphorylation in both the hippocampus and frontal cortex. Chronic fluoxetine did not influence activin $\beta$ A expression, but fluoxetine as well as desipramine did increase Smad2 phosphorylation in the frontal cortex. The functional significance of increased activin was further tested by examining the effects of activin infusions into the hippocampus on a behavioral model of depression, the forced swim test (FST). A single bilateral infusion of activin A or activin B into the dentate gyrus of the hippocampus produced an antidepressant-like effect in the FST that was comparable in magnitude with fluoxetine. In contrast, infusion of the activin antagonist inhibin A did not influence behavior but blocked the effect of activin A. The results suggest that regulation of activin and Smad signaling may contribute to the actions of antidepressant treatment and may represent novel targets for antidepressant drug development.
\end{abstract}

Key words: antidepressant; cytokine; dentate gyrus; neurotrophic; seizure; TGF- $\beta$ signaling

\section{Introduction}

Mood disorders are one of the most common forms of mental illness, affecting as much as $17 \%$ of the United States population, and are a leading cause of suicide (Kessler et al., 1994). Stress, emotional trauma, and environmental and genetic factors have all been implicated in precipitating depression (Duman et al., 2000, 2001; Manji et al., 2001; Nestler et al., 2002), but the underlying causes of depression are still unknown. Moreover, not all patients respond adequately to available medications, which also produce side effects and require weeks or months to achieve a therapeutic response.

Although the mechanisms underlying the actions of antidepressants have not been elucidated, it is hypothesized that adaptations to elevated monoamine levels are necessary and could provide important clues for developing more effective medications (Duman et al., 2000; Nestler et al., 2002). Upregulation of neurotrophic factors by antidepressant treatment and atrophy of limbic brain regions in response to stress or in depressed patients has resulted in a neurotrophic hypothesis of depression (Duman

\footnotetext{
Received Dec. 17, 2004; revised April 7, 2005; accepted April 8, 2005.

We acknowledge Mounira Banasr, Joshua Hunsberger, Rachel Jones, Ja Wook Koo, Jennifer Warner, and Gerald Valentine for excellent technical assistance.

Correspondence should be addressed to Dr. Ronald S. Duman, Laboratory of Molecular Psychiatry, Departments of Psychiatry and Pharmacology, Yale University School of Medicine, 34 Park Street, New Haven, CT 06508. E-mail: ronald.duman@yale.edu.

D0I:10.1523/JNEUROSC1.5155-04.2005

Copyright $\odot 2005$ Society for Neuroscience $\quad$ 0270-6474/05/254908-09\$15.00/0
}

et al., 1997, 2000; Duman, 2004). To extend this hypothesis, we have examined other classes of growth factors. One factor of interest is activin $\beta \mathrm{A}$, which is upregulated by acute electroconvulsive seizures (ECSs), the most effective treatment for depression, including patients who are resistant to chemical antidepressants (Andreasson and Worley, 1995).

Activin $\beta$ A and its isoforms are members of the transforming growth factor- $\beta$ (TGF- $\beta$ ) family, multifunctional growth factors that have a role in the regulation of key developmental events, as well as disease and repair in the adult brain (Bottner et al., 2000). Other activin subunits include activin $\beta \mathrm{B}$ and inhibin $\alpha$ that can also homodimerize and heterodimerize to form activin $B$, activin $A B$, inhibin A, or inhibin B (Pangas and Woodruff, 2000). Activin evokes a cellular response by binding to specific serine/threonine kinase receptors resulting in phosphorylation of the intracellular receptor-associated protein Smad2 or Smad3, which in conjunction with Smad4 can regulate transcriptional responses (Itoh et al., 2000; Pangas and Woodruff, 2000).

Growing evidence suggests that activin A may play a role in neuroprotection. In vitro, activin A has been shown to support the survival of neurogenic clonal cell lines and retinal neurons (Schubert et al., 1990), midbrian dopaminergic neurons (Krieglstein et al., 1995), cultured hippocampal neurons (Iwahori et al., 1997), and cultured amygdala neurons (Trudeau et al., 1997). In vivo, activin $\beta \mathrm{A}$ mRNA is induced in the hippocampus as a result of excitotoxic (Inokuchi et al., 1996; Tretter et al., 1996) and hypoxic-ischemic (Lai et al., 1996) injury and may be neuropro- 
tective, because infusions of activin A reduce neuronal damage after these injuries (Wu et al., 1999; Tretter et al., 2000).

These findings indicate that activin A could contribute to the efficacy of ECS and help block or reverse the atrophy that is caused by stress (Duman, 2004). In this study, we demonstrate that chronic ECS increases activin $\beta A$ mRNA and phosphorylation of Smad and that infusion of activin A produces an antidepressant-like response in a behavioral model of depression.

\section{Materials and Methods}

Animal treatment paradigms. Male Sprague Dawley rats with initial weights of 225-300 g (Charles River, Wilmington, MA) were group housed and maintained on a $12 \mathrm{~h}$ light/dark cycle with ad libitum access to food and water. All procedures were in accordance with Yale Animal Care and Use Committee and National Institutes of Health guidelines for animal research. Rats were administered electroconvulsive shock (60 $\mathrm{mA}, 0.5 \mathrm{~s}$ ) via earclip electrodes or received sham treatment (handled identically as those that received ECS, but without electrical stimulation). For acute treatment, rats were given one ECS and decapitated at 0.5, 1, 2, 6 , or $24 \mathrm{~h}$ after the seizure. For chronic treatment, rats were given 10 ECSs and decapitated at $6 \mathrm{~h}$ after the last seizure. Drug treatment was administered exactly as described by Kodama et al. (2005). Groups of rats were administered either fluoxetine $(5 \mathrm{mg} \cdot \mathrm{kg} \cdot \mathrm{d})$ or desipramine $(10$ $\mathrm{mg} \cdot \mathrm{kg} \cdot \mathrm{d}$ ) in the drinking water for $21 \mathrm{~d}$ (drugs are readily soluble in water). These doses of fluoxetine and desipramine were chosen because similar doses have been used previously for analysis of the molecular actions of antidepressants (Nibuya et al., 1995, 1996). Fluid intake was measured three times per week, and drinking bottles were filled with fresh drug solution. All animals consumed approximately the same amount of the drug-drinking water solution, and there was no difference in fluid intake among the treatment groups. In a previous study using this paradigm, drug levels were determined to be between 100 and $150 \mathrm{ng} / \mathrm{ml}$ plasma, which is in the range of drug levels achieved in patients (Kodama et al., 2005). Animals were decapitated on day 21, and brains were removed and frozen immediately for in situ hybridization or the frontal cortex and hippocampus were dissected for protein to be analyzed by Western blot. Because of continued intake of drug in the drinking water, it was not possible to conduct a discrete time course as was done after acute ECS.

In situ hybridization analysis. Coronal brain sections $(14 \mu \mathrm{m})$ were hybridized with ${ }^{35} \mathrm{~S}$-labeled activin riboprobes $\left(2 \times 10^{6} \mathrm{cpm} / \mathrm{section}\right)$ for $18 \mathrm{~h}$ at $60^{\circ} \mathrm{C}$ in hybridization buffer containing $50 \%$ formamide, $0.6 \mathrm{M}$ $\mathrm{NaCl}, 10 \mathrm{~mm}$ Tris, $1 \times$ Denhardt's solution, $2 \mathrm{~mm}$ EDTA, $10 \mathrm{~mm}$ dithiothreitol, $10 \%$ dextran sulfate, $50 \mu \mathrm{g} / \mathrm{ml}$ salmon sperm DNA, and 250 $\mathrm{mg} / \mathrm{ml}$ tRNA. After hybridization, the sections were washed in $2 \times \mathrm{SSC}$ at $25^{\circ} \mathrm{C}$ and treated with $20 \mathrm{mg} / \mathrm{ml} \mathrm{RNase}$ A for $30 \mathrm{~min}$ in $0.5 \mathrm{M} \mathrm{NaCl}, 10 \mathrm{~mm}$ Tris, and $1 \mathrm{~mm}$ EDTA. The sections were then washed in $0.2 \times$ SSC for 20 min at $60^{\circ} \mathrm{C}, 0.1 \times \mathrm{SSC}$ for $15 \mathrm{~min}$ at $60^{\circ} \mathrm{C}$, and $0.1 \times \mathrm{SSC}$ for $1 \mathrm{~min}$ at $25^{\circ} \mathrm{C}$ and rinsed in deionized $\mathrm{H}_{2} \mathrm{O}$. The sections were dried and exposed to Kodak Biomax film (Kodak, Rochester, NY), and the density of the dentate gyrus, CA1, and frontal cortex was measured using NIH Image. The riboprobes were generated by PCR amplification from rat ovarian tissue, which expresses high levels of activin, and contained T3 and T7 sequences for sense and antisense transcription, respectively. The primers used were as follows: activin $\beta$ A sense, $5^{\prime}$-GAATTAACCCTCACTAAAGGGCCTTCCGAAGGATGGACCTAACTC; activin $\beta$ A antisense, 5'-GTAATACGACTCACTATAGGGCAAAGGTGATGATCTCCGAGG; activin $\beta$ B sense, $5^{\prime}$-GAATTAACCCTCACTAAAGGGCAGAGACAGATGGCCTCGCCTCC; activin $\beta$ B antisense, $5^{\prime}$-GTAATACGACTCACTATAGGGCGTTTTAGGTCCACCTTCTTCTC. Both sense and antisense probes were tested on ovarian tissue because expression of activin mRNA is well described for this tissue and is in higher abundance than in rat. Specificity of the antisense probe signal was confirmed by the absence of label when sections were instead incubated with radiolabeled sense probe (data not shown).

Western blot. Hippocampus and frontal cortex samples were sonicated in $20 \mathrm{~mm}$ Tris, pH 7.4, $150 \mathrm{~mm} \mathrm{NaCl}, 1 \%$ SDS, 5 mм EDTA, 5 mм EGTA, $2 \mu \mathrm{g} / \mathrm{ml}$ aprotinin, $2 \mu \mathrm{g} / \mathrm{ml}$ pepstatin $\mathrm{A}, 10 \mu \mathrm{g} / \mathrm{ml}$ leupeptin, $10 \mathrm{~mm} \mathrm{NaF}$,
$1 \mathrm{~mm} \mathrm{NaVO}_{3}$, and $5 \mathrm{~mm}$ sodium pyrophosphate. The Lowry method (Lowry et al., 1951) was used to determine the protein concentration of the samples. Equal amounts of total protein were separated on $7.5 \%$ SDS-polyacrylamide gels and transferred to nitrocellulose membranes. Blots were blocked for $1 \mathrm{~h}$ in 5\% powdered milk in TBS and incubated overnight at $4^{\circ} \mathrm{C}$ in primary antibody. Blots were washed and incubated for $1 \mathrm{~h}$ in the appropriate peroxidase-labeled secondary antibody (Vector Laboratories, Burlingame, CA) in 5\% milk in TBS. Bands were visualized with chemiluminescence and exposed to Hyperfilm MP (Amersham Biosciences, Piscataway, NJ). The intensity of the bands were quantified using NIH Image. Calibration was performed using a control density filmstrip from Kodak. The primary antibodies used were a rabbit antiphospho-Smad2 (Ser465/467; Upstate Cell Signaling Solutions, Lake Placid, NY), a monoclonal anti-Smad2 (Cell Signaling, Beverly, MA), and a monoclonal anti-Smad4 (Santa Cruz Biotechnology, Santa Cruz, CA). The antibodies recognized bands of the correct size in a concentration-dependent manner (data not shown).

Surgical procedure and infusions. Aseptic surgery was performed in a stereotaxic apparatus (Kopf Instruments, Tujunga, CA) as described by Taylor and Horger (1999). Stainless steel double guide cannulas (22 gauge) were implanted under anesthesia with pentobarbital sodium solution (50 mg/kg, i.p.; Abbott Laboratories, North Chicago, IL). Double dummy cannulas were placed temporarily in the guide cannulas to prevent occlusion. The coordinates for the dentate gyrus and CA1 [relative to bregma according to the atlas of Paxinos and Watson (1998)] were as follows: -3.8 anteroposterior (AP), \pm 1.9 lateral to the midline, and -2.1 dorsoventral (DV) from dura and $-3.8 \mathrm{AP}, \pm 1.9$ lateral to the midline, and $-1.1 \mathrm{DV}$ from dura, respectively. Animals were allowed to recover for $7 \mathrm{~d}$ after surgery before being used for behavioral testing.

Rats received bilateral microinfusions of activin A $(0.5 \mu \mathrm{g} /$ side or 1.0 $\mu \mathrm{g} /$ side; carrier free; R \& D Systems, Minneapolis, MN) in $0.1 \%$ BSA in PBS, activin B (1.0 $\mu \mathrm{g} / \mathrm{side}$; carrier free; R \& D Systems) in $0.1 \%$ BSA in PBS, inhibin A ( $1.0 \mu \mathrm{g} / \mathrm{side}$; not carrier free; Diagnostic Systems Laboratories, Webster, TX) in 5\% BSA in PBS, a coinfusion of activin A and inhibin A (1.0 $\mu \mathrm{g}$ of each/side) in 5\% BSA in PBS, $0.1 \%$ BSA in PBS (vehicle for activin A and B), or 5\% BSA in PBS (vehicle for inhibin A). Because inhibin A was received in 5\% BSA, animals infused with $0.1 \%$ BSA were compared with animals infused with $5 \%$ BSA. No difference was seen between the two groups in the forced swim test (FST), and therefore the data were combined in Figure 6. Injection cannulas (28 gauge) were attached to PE-20 polyethylene tubing (Clay Adams, Sparks, $\mathrm{MD}$ ) and lowered manually through the guide cannulas to $1.0 \mathrm{~mm}$ below the guide. The vehicle or growth factors were delivered by microdrive pump (Harvard Apparatus, South Natick, MA) with $10 \mu$ l Hamilton microsyringes (Hamilton, Reno, NV). A total volume of $1.0 \mu \mathrm{l}$ was infused into each side over $10 \mathrm{~min}$, and the injection cannulas were left in place for an additional $5 \mathrm{~min}$ to allow for diffusion. The injection cannulas were removed and replaced with the dummy cannulas. Rats were hand-held during the infusions. The placement of the cannulas was determined by cryostat sectioning through the infusion site. Any behavioral data generated from animals in which the cannulas track was not in the correct area were excluded.

FST. A modified rat FST was performed as described previously (Porsolt et al., 1977; Detke et al., 1995). This is a standard behavioral test that is used as a screen to find antidepressant-like compounds. On day 1 ( 1 week after cannulation surgery), the animals were placed individually in a clear cylinder $(25 \mathrm{~cm}$ diameter, $65 \mathrm{~cm}$ height $)$ with water at a depth of 45 $\mathrm{cm}\left(23-25^{\circ} \mathrm{C}\right)$ for $15 \mathrm{~min}$. The rats were removed from the water, dried, and placed in a warmed cage for $30 \mathrm{~min}$. For antidepressant treatments, fluoxetine $(30 \mathrm{mg} / \mathrm{kg})$, desipramine $(30 \mathrm{mg} / \mathrm{kg})$, or $0.9 \%$ saline was administered by intraperitoneal injections $0.5,19$, and $23 \mathrm{~h}$ after the first exposure. Thirty minutes after the first exposure to the FST, rats received bilateral infusions of activin $\mathrm{A}$, activin $\mathrm{B}$, inhibin $\mathrm{A}$, a combination of activin A and inhibin A, 0.1\% BSA in PBS, or 5\% BSA in PBS as described above. On day 2 ( $24 \mathrm{~h}$ after the first exposure), the rats were placed back into the water for $5 \mathrm{~min}$, and the sessions were videotaped from the side. A behavioral sampling technique was used (Detke et al., 1995; Mague et al., 2003) to rate the predominant behavior in each $5 \mathrm{~s}$ interval of the $300 \mathrm{~s}$ test. Three behaviors were scored using the following criteria (Lucki, 
1997): (1) climbing was scored when the rat made forceful thrashing movements with the forepaws along the side of the swim chamber; (2) swimming was scored when the rat moved throughout the cylinder and crossed into another quadrant; and (3) immobility was scored when the rat made no additional movement, then was required to keep the rat's head above the water.

Locomotor activity. Automated activity meters (Digiscan animal activity monitor; Omnitech Electronics, Columbus, $\mathrm{OH}$ ) were used to determine locomotor activity. The activity meters were equipped with two parallel rows of infrared photosensors (each row consists of 16 sensors $2.5 \mathrm{~cm}$ apart) and were controlled by a personal computer using the Micropro software (Omnitech Electronics). The first day of the locomotor study was conducted exactly as the FST studies. On day 1, animals underwent the $15 \mathrm{~min}$ forced swim and were given bilateral infusions $30 \mathrm{~min}$ later. Instead of being placed back into the cylinders on day 2, animals were placed in transparent plastic boxes that were fitted into the activity meters. Locomotor activity was recorded for $60 \mathrm{~min}$.

Immunohistochemistry. Animals were perfused 1, 3, or $24 \mathrm{~h}$ after activin A infusions into the dentate gyrus. Serial coronal sections of the brains were cut $(40 \mu \mathrm{m})$ through the hippocampus on a freezing microtome, and sections were stored at $-20^{\circ} \mathrm{C}$ in $50 \%$ ethylene glycol, $150 \mathrm{~mm}$ KPBS, and 20\% glycerol. Freefloating sections were washed three times for 5 $\min$ in $1 \times$ PBS, incubated for $10 \mathrm{~min}$ in $0.6 \%$ hydrogen peroxide in $1 \times$ PBS, washed three times for $5 \mathrm{~min}$ in $1 \times$ PBS, and blocked for $1 \mathrm{~h}$ in $1 \times$ PBS containing $2 \%$ bovine serum, $5 \%$ normal horse serum, and $0.2 \%$ Triton $\mathrm{X}-100$ for blocking. Sections were incubated with pri-

Figure 1. Acute ECS increases levels of activin $\beta A$ mRNA in the hippocampus and cortex. Levels of activin $\beta A$ and $\beta B$ mRNA were determined by in situ hybridization analysis as described in Materials and Methods. A, Representative autoradiograms illustrate the time course for induction of activin $\beta A$ mRNA in the dentate gyrus, superficial layer of the cortex, and deep layer of the cortex. The bar graphs show the optical density (OD) values for the mRNA levels $(n=4-5$ per group). DG, $F_{(4,18)}=263.38, p<0.0001 ; S L, F_{(4,17)}=5.756$, $p<0.01 ; \mathrm{DL}, F_{(4,17)}=1.917, p>0.05$. B, Representative autoradiograms illustrate the time course of induction of activin $\beta A$ mRNA in the frontal cortex. Arrowheads indicate superficial layers of the cerebral cortex. The bar graph shows the $O D$ values for the mRNA levels ( $n=4-5$ per group). $F_{(4,18)}=31.08 ; p<0.0001$. C, Representative autoradiograms illustrate that acute ECS does not increase levels of activin $\beta B$ mRNA in the dentate gyrus of the hippocampus at any time point examined but does increase levels in the $C A 1$ of the hippocampus at $2 \mathrm{~h}$ after seizure. The bar graph shows the $0 D$ values for the mRNA levels ( $n=4-5$ per group). DG, $F_{(4,17)}=1.122, p>0.05 ; C^{(A} 1, F_{(4,17)}=4.752, p<0.01$. The results are the mean \pm SEM. ${ }^{*} p<0.05,{ }^{* * *} p<0.001$ compared with $0 \mathrm{~h} ;{ }^{++} p<0.01,{ }^{+++} p<0.001$ compared with $2 \mathrm{~h}$ (ANOVA and Newman-Keuls test). DG, Dentate gyrus; SL, superficial layer of the cortex; DL, deep layer of the cortex.
A.
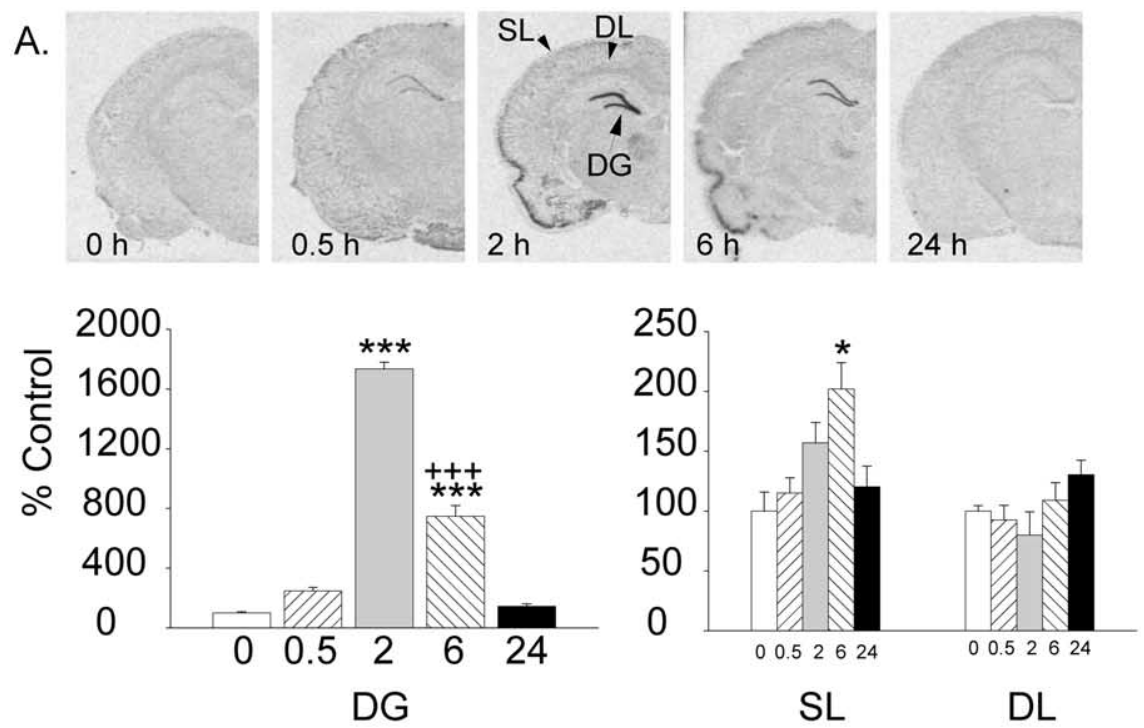

B.
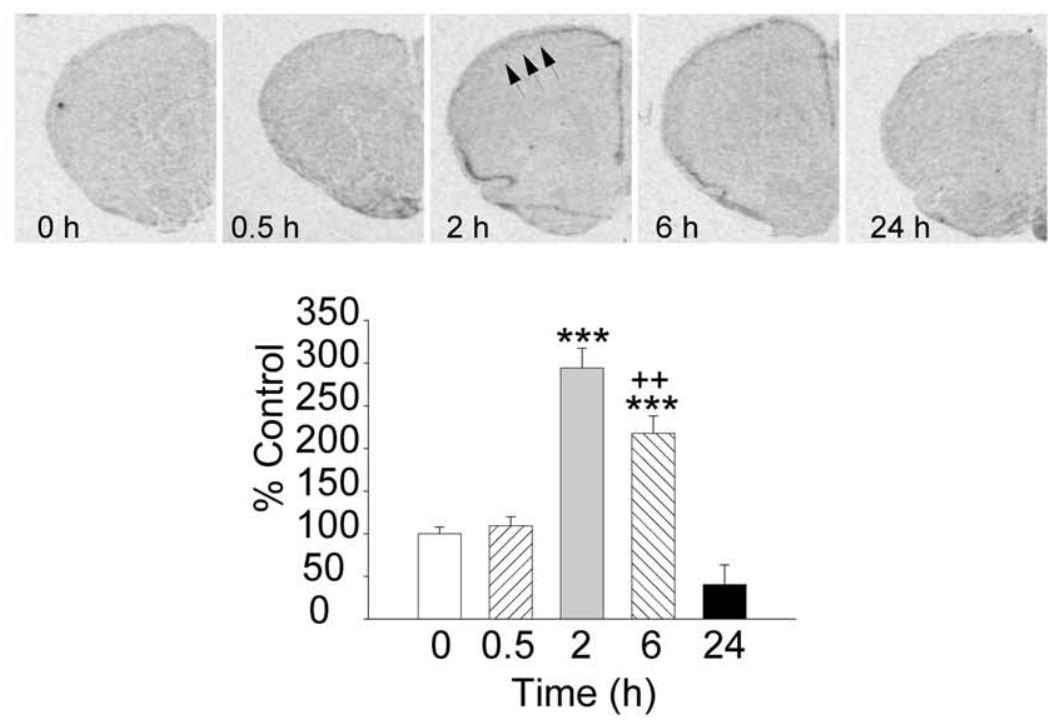

C.
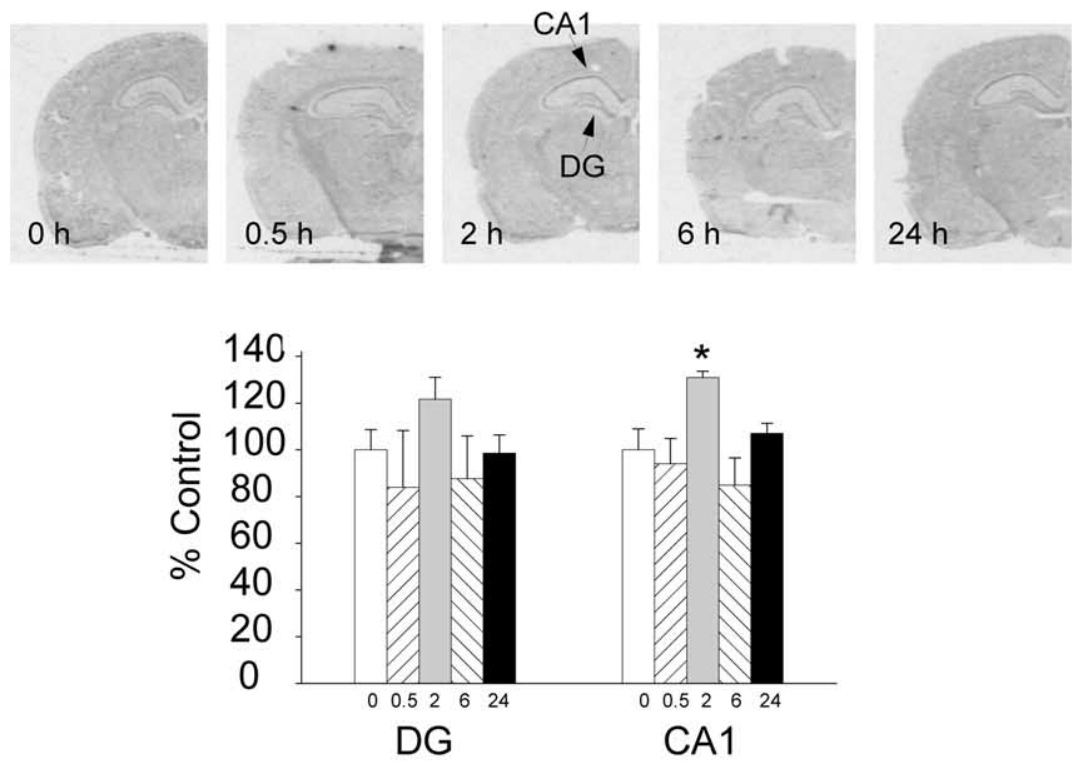

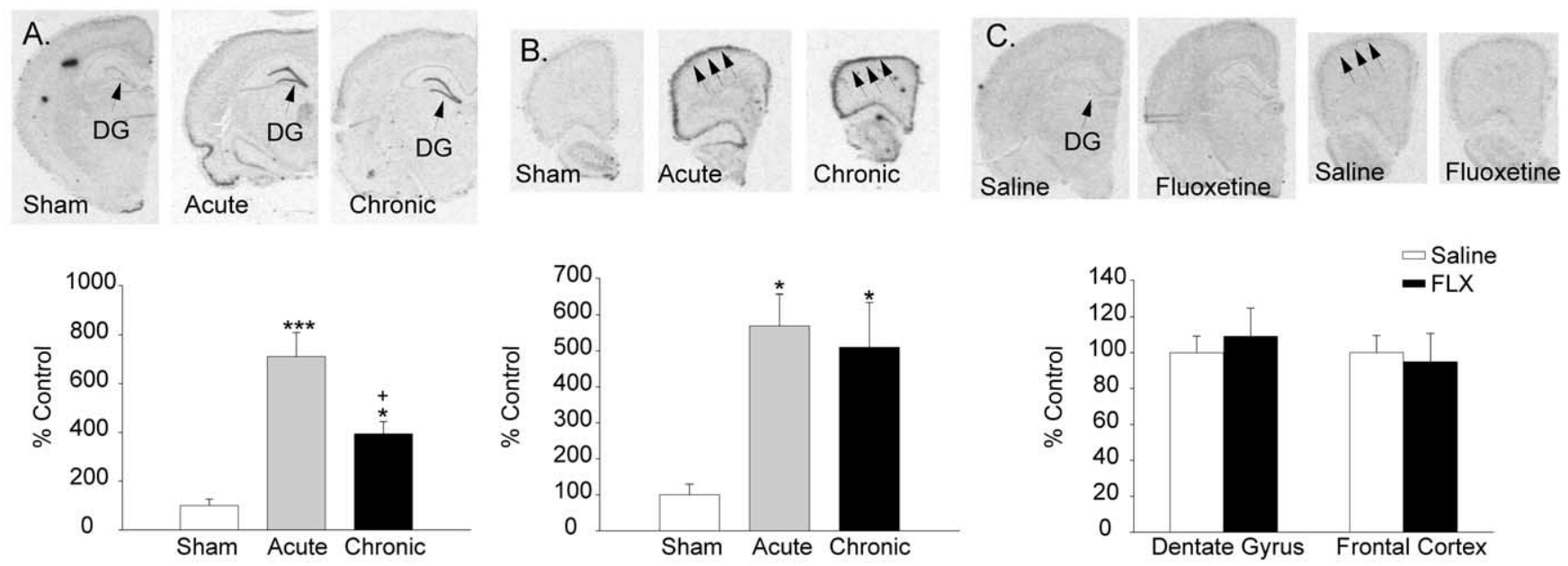

Figure 2. Influence of chronic ECS or fluoxetine on levels of activin $\beta A$ mRNA in the hippocampus and cerebral cortex. Levels of activin $\beta A$ mRNA were determined by in situ hybridization analysis as described in Materials and Methods. $A$, Representative autoradiograms illustrate the induction of activin $\beta A$ mRNA in the dentate gyrus after both acute and chronic ECS. The bar graph shows the optical density (OD) values for the mRNA levels ( $n=5-6$ per group). $F_{(2,14)}=18.7646, p<0.001$. $\boldsymbol{B}$, Representative autoradiograms illustrate the induction of activin $\beta$ A mRNA in the frontal cortex after both acute and chronic ECS. Triple arrowheads indicate the superficial layers of the cerebral cortex. The bar graph shows the OD values for the mRNA levels $\left(n=5-6\right.$ per group). $F_{(2,14)}$ $=8.2985, p<0.01$. C, Representative autoradiograms illustrate that there is no difference in activin $\beta$ A mRNA levels after fluoxetine $(5 \mathrm{mg} \cdot \mathrm{kg} \cdot \mathrm{d})$ treatment in the hippocampus (left two panels) or the frontal cortex (right two panels). The graph shows the 0D values for the mRNA levels ( $n=6$ per group). DG, $F_{(1,10)}=0.4732, p>0.05 ;$ frontal cortex, $F_{(1,10)}=0.0522, p>0.05$. The results are the mean \pm SEM. ${ }^{*} p<0.05,{ }^{* * *} p<0.001$ compared with sham; ${ }^{+} p<0.05$ compared with acute (ANOVA and Newman-Keuls test). DG, Dentate gyrus; FLX, fluoxetine.

\section{A. Hippocampus: Acute Time Course}

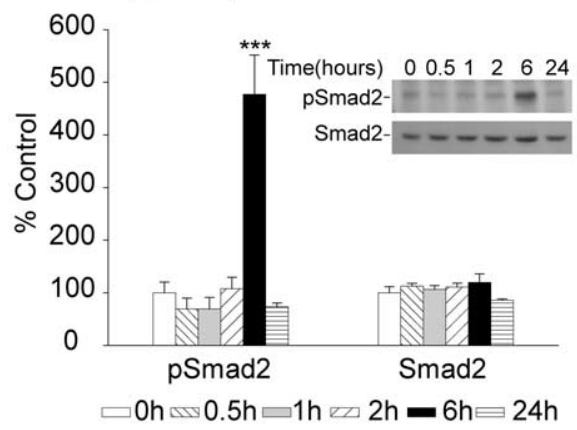

C. Hippocampus: Acute vs Chronic ECS

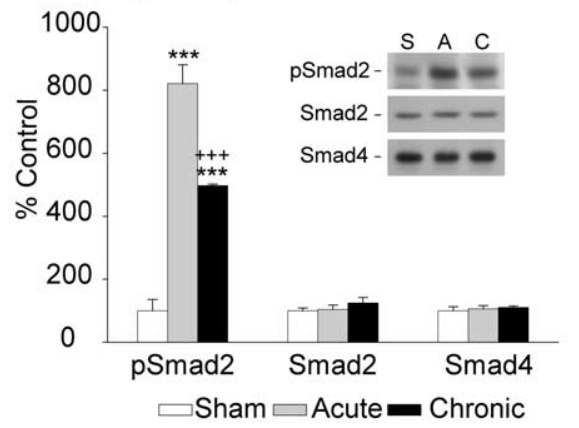

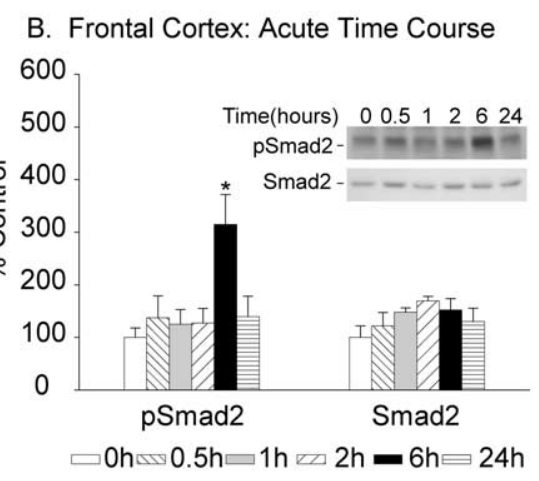

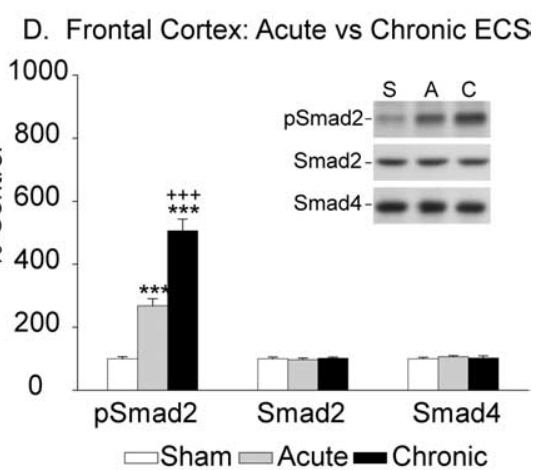

mary monoclonal anti-activin A antibody (1: 400; R \& D Systems) for $72 \mathrm{~h}$ at $4^{\circ} \mathrm{C}$. Sections were washed six times for $5 \mathrm{~min}$ in $1 \times \mathrm{PBS}$, incubated in secondary antibody (biotinylated anti-mouse; Vector Laboratories), washed six times for $5 \mathrm{~min}$ in $1 \times \mathrm{PBS}$, incubated with an avidin-biotin complex (Vectastain Elite ABC kit; Vector Laboratories), washed six times for 5 min in $1 \times$ PBS, and visualized with DAB (Vector Laboratories).

Statistical analysis. Experiments with two groups were compared with unpaired Student's $t$ test. Experiments with three or more groups were subjected to a two-way ANOVA, followed by the post hoc Newman-Keuls multiple comparisons test. Locomotor activity data were analyzed using the repeated-measures ANOVA with time being the repeated measure.

\section{Results}

Regulation of activin $\beta \mathrm{A}$ induction by antidepressant treatment

Consistent with previous reports, we found that activin $\beta \mathrm{A}$ mRNA was increased in the dentate gyrus of the hippocampus after acute ECS in a timedependent manner (Andreasson and Worley, 1995). Activin $\beta A$ mRNA was induced at $2 \mathrm{~h}$, but not $30 \mathrm{~min}$, after acute ECS, continued to be increased at $6 \mathrm{~h}$, and was back to baseline by $24 \mathrm{~h}$ (Fig. $1 A$ ). In addition to the hippocampus, the frontal cortex is another limbic brain structure that has been implicated in the etiology and treatment of mood disorders (Duman et al., 2000, 2001; Manji et al., 2001; Nestler et al., 2002). An increase in activin $\beta A$ mRNA in the superficial layers of the frontal cortex after acute ECS was observed at 2

Figure 3. Phosphorylation of Smad2 is increased in the hippocampus and frontal cortex after ECS. Levels of pSmad2, Smad2, and Smad4 were determined by Western blot analysis as described in Materials and Methods. $\boldsymbol{A}$, Representative immunoblots illustrate the (OD) values for pSmad2 and Smad2 ( $n=4$ per group). $p S m a d 2, F_{(5,18)}=20.739, p<0.0001 ; \operatorname{Smad2}, F_{(5,18)}=1.2694, p>0.05 . B_{\text {, }}$ Representative immunoblots illustrate the time course of induction of $\mathrm{pS}$ mad2 in the frontal cortex. There is no change in total Smad2 levels. The bar graph shows the $0 D$ values for $p S \operatorname{smad} 2$ and $S \operatorname{mad} 2$ ( $n=3-4$ per group). $p S \operatorname{smad} 2, F_{(5,17)}=4.4753, p<0.01 ; S \operatorname{Smad2}$ $F_{(5,17)}=1.4499, p>0.05$. C, Representative immunoblots illustrate the increased levels of $p S m a d 2$ in the hippocampus $6 \mathrm{~h}$ after acute and chronic ECS. The bar graph shows the OD values for pSmad2, Smad2, and Smad4 ( $n=4$ per group). pSmad2, $F_{(2,9)}=80.606, p<$ $0.0001 ; S m a d 2, F_{(2,9)}=0.8532, p>0.05 ; S m a d 4, F_{(2,9)}=0.2916, p>0.05$. D, Representative immunoblots illustrate the increased levels of $\mathrm{pS}$ mad2 in the frontal cortex $6 \mathrm{~h}$ after acute and chronic ECS. The bar graph shows the $0 D$ values for $\mathrm{pS}$ mad2, Smad2, and $S$ mad4 $\left(n=5-6\right.$ pergroup). $p S m a d 2, F_{(2,14)}=66.263, p<0.0001 ; S \operatorname{mad} 2, F_{(2,14)}=0.2544, p>0.05 ; S \operatorname{Smad} 4, F_{(2,14)}=0.4226, p>0.05$. The results are the mean \pm SEM. ${ }^{*} p<0.05,{ }^{* * *} p<0.001$ compared with the sham treatment; ${ }^{+++} p<0.001$ compared with acute ECS (ANOVA and Newman-Keuls test). S, Sham; A, acute; C, chronic. 
and $6 \mathrm{~h}$ after acute ECS (Fig. 1 B). A similar effect was observed in the superficial layer of the parietal cortex adjacent to the hippocampus (Fig. 1A) $6 \mathrm{~h}$ after ECS, and there was a trend for an increase at $2 \mathrm{~h}$, with no difference in expression levels in the deep layers of the cerebral cortex. Consistent with Andreasson and Worley (1995), activin $\beta$ B mRNA was not induced in the dentate gyrus; however, we did find a small but significant increase in activin $\beta$ B expression in the CA1 (Fig. 1C).

Because the therapeutic actions of ECS are dependent on repeated treatment, the influence of 10 daily ECSs was compared with one ECS or sham treatment. Animals were decapitated $6 \mathrm{~h}$ after their last ECS. Chronic administration of ECS also resulted in an increase in activin $\beta$ A mRNA in the dentate gyrus, although the induction was smaller than after acute treatment (Fig. $2 A$ ). In addition, activin $\beta \mathrm{A}$ mRNA was increased to similar levels in the superficial layer of the frontal cortex after either acute or chronic ECS (Fig. 2B). Again, there was no induction of activin $\beta \mathrm{B}$ mRNA after chronic treatment (data not shown). We also tested the influence of fluoxetine, a serotonin-selective reuptake inhibitor antidepressant. Fluoxetine treatment (21 d) had no effect on activin $\beta$ A mRNA levels in either the hippocampus or the frontal cortex (Fig. 2C). This suggests that activin $\beta$ A may be a unique target for ECS.

\section{Regulation of Smad2 phosphorylation by antidepressant treatment}

The primary signaling target of activin A is Smad2. Binding of activin to its receptor leads to phosphorylation of Smad2 (pSmad2), which associates with Smad4 and translocates to the nuclease where the complex associates with DNAbinding subunits and regulates the transcription of target genes (Itoh et al., 2000; Pangas and Woodruff, 2000). Therefore, pSmad 2 can be used as an indicator of pathway activation. In contrast to the time course shown for activin $\beta \mathrm{A}$ mRNA induction in the hippocampus after acute ECS, increases in pSmad2 levels did not occur at $2 \mathrm{~h}$ or earlier time points but did occur at $6 \mathrm{~h}$ after ECS (Fig. 3A). This increase in phosphorylation returned to baseline at $24 \mathrm{~h}$ (Fig. $3 A$ ). There was no change in total Smad2 levels at any time point examined after ECS (Fig. $3 A$ ). In the frontal cortex, ECS increased levels of pSmad 2 with a similar pattern as that in the hippocampus (Fig. 3B). Again, there was no significant change in total Smad2 levels (Fig. 3B).

To determine whether chronic ECS results in altered regulation of pSmad2 compared with acute ECS, animals were again administered 10 or 1 daily ECS but were decapitated $6 \mathrm{~h}$ after their last ECS. Both acute and chronic ECS resulted in an increase in pSmad2, with no effect on total Smad2 or Smad4
B. Desipramine (21 d)

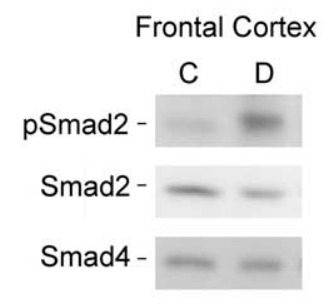

Frontal Cortex
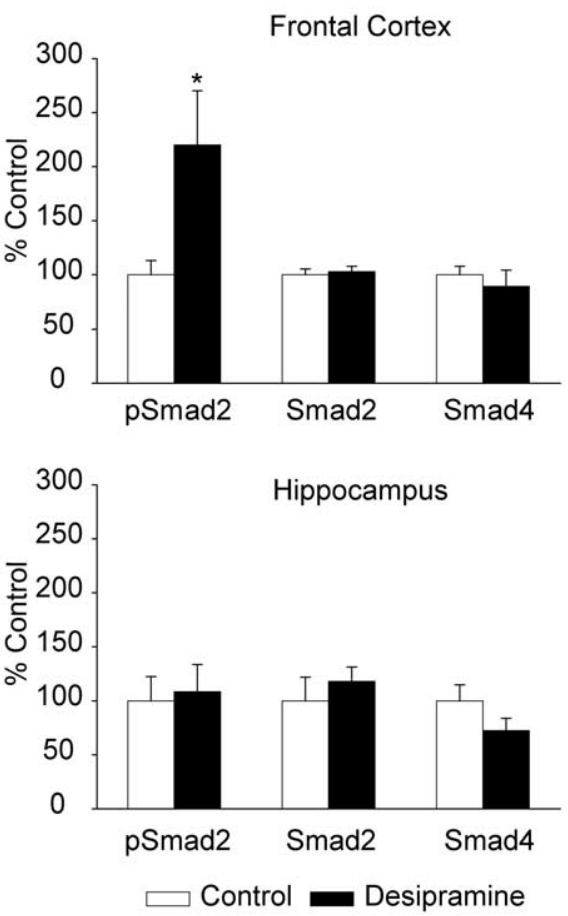

Figure 4. Fluoxetine and desipramine increase Smad2 phophorylation in the frontal cortex. Levels of pSmad2, Smad2, and Smad4 were determined by Western blot analysis as described in Materials and Methods. $A$, Representative immunoblots illustotal Smad2 or Smad4 levels. The graphs show the optical density (OD) values for pSmad2, Smad2, and Smad4 in both the fronta the hippocampus ( $n=6$ per group). Frontal cortex: $p S \operatorname{mad} 2, F_{(1,10)}=5.181, p<0.05 ; \operatorname{Smad2}, F_{(1,10)}=0.0052, p>$ $F_{(1,0)}=2.18, p>0.05$. B Representative immunoblots illustrate the increased level of $p S$ mad 2 in the frontal cortex as a result of desipramine $(10 \mathrm{mg} \cdot \mathrm{kg} \cdot \mathrm{d})$ treatment with no difference in total Smad2 or Smad4 levels. The bar graphs show the OD values for pSmad2, Smad2, and Smad4 in both the frontal cortex and the hippocampus ( $n=6$ per group). Frontal cortex: pSmad2, $F_{(1,10)}=5.3699, p<0.05 ;$ Smad2, $F_{(1,10)}=0.1563, p>0.05 ;$ Smad4, $F_{(1,10)}=0.4124, p>0.05$; hippocampus: pSmad2, $F_{(1,10)}=0.0636, p>0.05 ; S \operatorname{Smad2}, F_{(1,10)}=0.4919, p>0.05 ; S m a d 4, F_{(1,10)}=2.183, p>0.05$. The results are the mean \pm SEM. ${ }^{*} p<0.05$ compared with the corresponding controls (Student's $t$ test). C, Control; F, fluoxetine; D, desipramine.

levels in either the hippocampus or frontal cortex (Fig. 3C,D). In the hippocampus, acute ECS resulted in a significantly greater increase in $\mathrm{pSmad} 2$ than chronic ECS (Fig. 3C). However, in the frontal cortex, pSmad2 levels were significantly higher after chronic ECS then after acute ECS (Fig. 3D). Although activin $\beta$ A mRNA levels were not induced as a result of fluoxetine treatment, pSmad2 levels were significantly increased in the frontal cortex but not the hippocampus after fluoxetine treatment (Fig. 4A). No difference in total Smad2 levels or Smad4 levels were observed after fluoxetine treatment (Fig. 4A). In addition to fluoxetine, the influence of desipramine, a norepinephrine-selective reuptake inhibitor, was also examined. Desipramine treatment also resulted in an increase in pSmad2 in the frontal cortex, but not the hippocampus, with no changes in total Smad2 levels or Smad4 levels (Fig. 4B). 


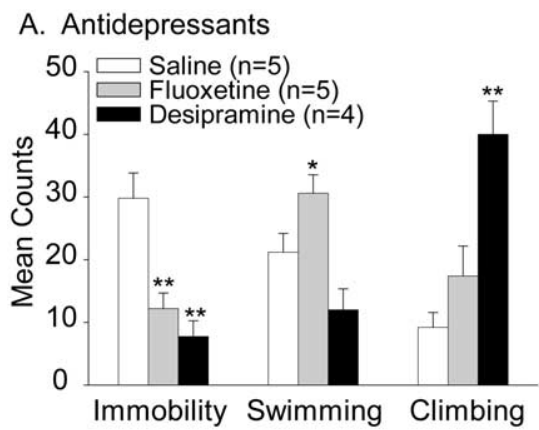

B. Infusions of Activin A into dentate gyrus

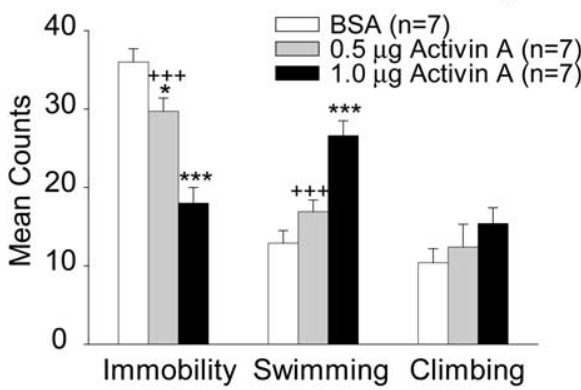

C. Infusion of Activin A into CA1

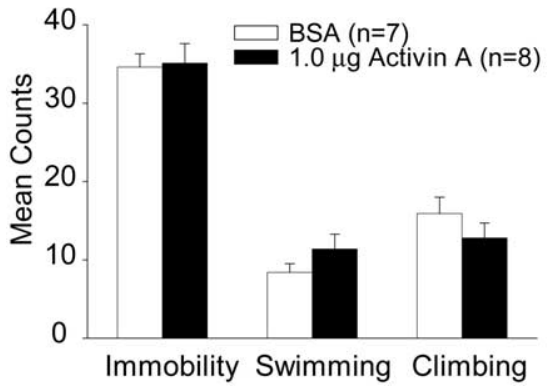

D. Infusion of Activin $B$ into dentate gyrus

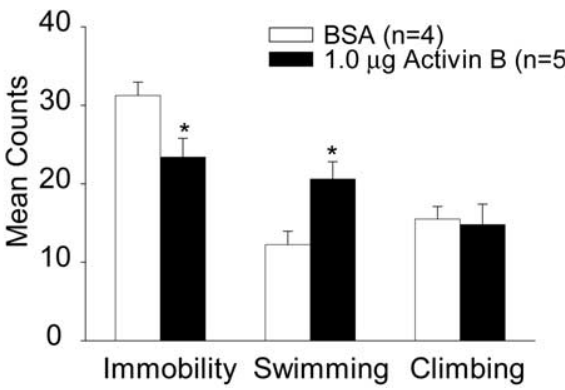

Figure 5. Infusions of activin A into the dentate gyrus of the hippocampus have an antidepressant effect in the FST. Animals were exposed to inescapable swimming for $15 \mathrm{~min}$ and $30 \mathrm{~min}$ later were administered the antidepressants or growth factors as indicated. $\boldsymbol{A}$, Fluoxetine and desipramine were administered by intraperitoneal injection three times over a $24 \mathrm{~h}$ period as described in Materials and Methods. Activin $A(B, C)$ activin $B(\boldsymbol{D})$, or $1 \%$ BSA were infused bilaterally into the dentate gyrus $(\boldsymbol{B}, \boldsymbol{D})$ or the $C A 1(C)$ of the hippocampus at the doses indicated. Animals were tested $24 \mathrm{~h}$ after the initial swimming session, and immobility, swimming, and climbing were scored. $A$, Immobility, $F_{(2,11)}=13.384, p<0.01$; swimming, $F_{(2,11)}=8.7833, p<$ 0.01 ; climbing, $F_{(2,11)}=13.356, p<0.01$. B, Immobility, $F_{(2,18)}=24.834, p<0.0001$; swimming, $F_{(2,18)}=17.437, p<$ 0.0001 ; climbing, $F_{(2,18)}=1.2034, p>0.05$. C, Immobility, $F_{(1,13)}=0.0313, p>0.05 ;$ swimming, $F_{(1,13)}=1.611, p>0.05$; climbing, $F_{(1,13)}=1.232, p>0.05$. D, Immobility, $F_{(1,7)}=6.479, p<0.05 ;$ swimming, $F_{(1,7)}=7.978, p<0.05 ;$ climbing, $F_{(2,18)}$ $=0.0465, p>0.05$. The results are expressed as mean \pm SEM. ${ }^{*} p<0.05$, ${ }^{* *} p<0.01$, ${ }^{* * *} p<0.001$ compared with the corresponding BSA- or saline-injected controls; ${ }^{+++} p<0.001$ compared with the $1.0 \mu \mathrm{g}$ activin A-infused animals (ANOVA and Newman-Keuls test).
Infusion of activin decreases immobility in the FST

The FST is a behavioral paradigm that is sensitive to antidepressant treatments. In FST, rats that have been exposed previously to swimming in an inescapable container of water spend a significant amount of time immobile when subsequently tested in the same container. This immobility is reversed by antidepressant treatment, with an increase in escape-oriented behavior such as swimming and climbing (Porsolt et al., 1977; Detke et al., 1995). Serotonin-selective reuptake inhibitors such as fluoxetine decrease immobility and increase swimming behavior, whereas norepinephrine-selective reuptake inhibitors such as desipramine decrease immobility and increase climbing (Fig. 5A) (Detke et al., 1995).

The effect of bilateral microinjections into the hippocampus of activin family members was determined. Because it has been shown that ECS produces a robust upregulation of activin $\beta \mathrm{A}$ mRNA in the dentate gyrus granule cell layer (Andreasson and Worley, 1995) (Figs. 1, 2), microinfusion of activin A in this subfield of the hippocampus was tested first. Activin A $(0.5$ or $1.0 \mu \mathrm{g} / \mathrm{side})$ or $0.1 \%$ BSA was infused bilaterally in the dentate gyrus $30 \mathrm{~min}$ after the rats' initial swimming session on day 1 , and the rats were tested $24 \mathrm{~h}$ later on day 2 . A single bilateral infusion of activin A into the dentate gyrus of the hippocampus $30 \mathrm{~min}$ after training produced a dose-dependent, antidepressant effect in the FST comparable in magnitude to that observed with administration of fluoxetine (Fig. $5 A, B$ ). Both 0.5 and $1.0 \mu \mathrm{g}$ of activin $\mathrm{A}$ into the dentate gyrus decreased the amount of time rats spent immobile, and there was a significant difference between the 0.5 and $1 \mu \mathrm{g}$ dose. Animals that received $1.0 \mu \mathrm{g}$ of activin $A$ also had a significant increase in swimming with no change in climbing (Fig. 5B).

To examine the regional specificity of this effect, the influence of activin A infusions into another subfield of the hippocampus was determined. Activin A $(1.0 \mu \mathrm{g})$ infused bilaterally into the CA1 pyramidal cell layer of the hippocampus did not influence immobility, suggesting that the effect in the dentate gyrus is region specific (Fig. 5C). To examine the specificity of activin isoforms on this behavior, $1.0 \mu \mathrm{g}$ of activin B and $1.0 \mu \mathrm{g}$ of inhibin A were bilaterally infused into the dentate gyrus. Similar to activin A, activin B infusions resulted in a decrease in immobility and an increase in swimming with no change in climbing (Fig. 5D). Inhibin A did not effect immobility time when infused alone but did reverse the effect of activin A (Fig. 6). The influence of activin A on locomoter activity was also determined to investigate whether the decrease in immobility could be attributable to a generalized effect on activity. Locomotor activity was examined over a 60 min time period. There was no significant effect of activin A relative to vehicle (Fig. 7).
Figure 6. Infusions of inhibin A into the dentate gyrus of the hippocampus did not effect immobility when infused alone but reversed the effect of activin $A$. Activin $A$, inhibin $A$, activin A plus inhibin $A$, or vehicle was infused into the dentate gyrus 30 min after the first swimming session and $24 \mathrm{~h}$ later were tested as described in Materials and Methods. Because there was no difference between $0.1 \% \mathrm{BSA}$ and $5 \% \mathrm{BSA}$ (vehicle for activin $\mathrm{A}$ or inhibin $\mathrm{A}$, respectively), the data were combined. The results are the mean \pm SEM. ${ }^{* * *} p<0.001$ compared with the corresponding BSA-infused controls; ${ }^{++} p<0.01,{ }^{++} p<0.001$ compared with activin A-infused animals (ANOVA and Newman-Keuls test). Immobility, $F_{(3,21)}=7.3664, p<0.01$; swimming, $F_{(3,21)}=13.316, p<0.0001$; climbing, $F_{(3,21)}=1.0550, p>0.05$. 


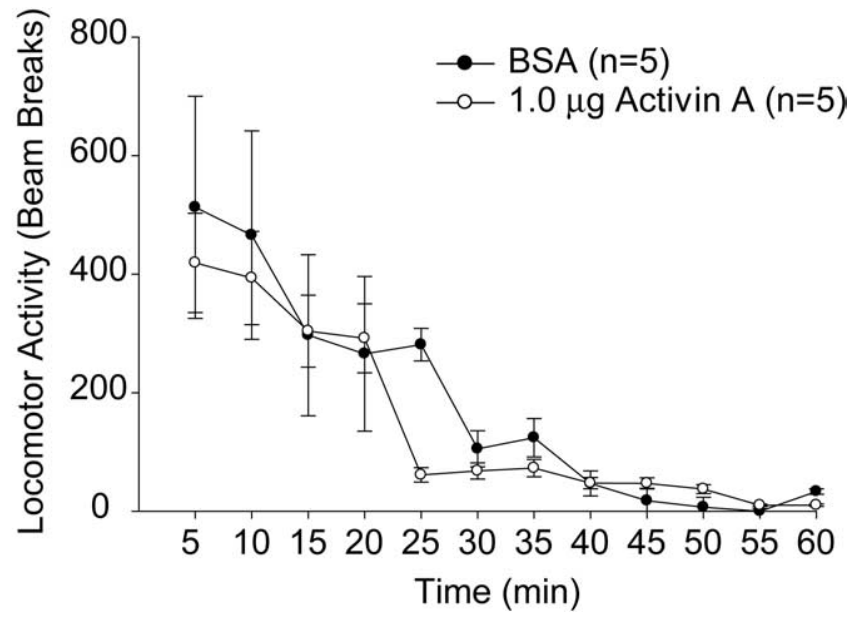

Figure 7. Influence of activin A infusion into the dentate gyrus of the hippocampus on locomotor activity. Activin A or $0.1 \%$ BSA in PBS was infused into the dentate gyrus 30 min after the first swimming session, and $24 \mathrm{~h}$ later, the total number of beam breaks in $5 \mathrm{~min}$ bins was recorded for a total of $60 \mathrm{~min}$. The results are the mean \pm SEM. Treatment, $F_{(1,8)}=0.573, p>$ 0.05 ; time, $F_{(11,88)}=21.766, p<0.0001$; treatment $\times$ time, $F_{(11,88)}=1.025, p>0.05$. There was a significant decrease in locomotor activity for both groups over time as the animals habituated to the test chambers, but there was no significant treatment by time interaction (repeated-measures ANOVA).
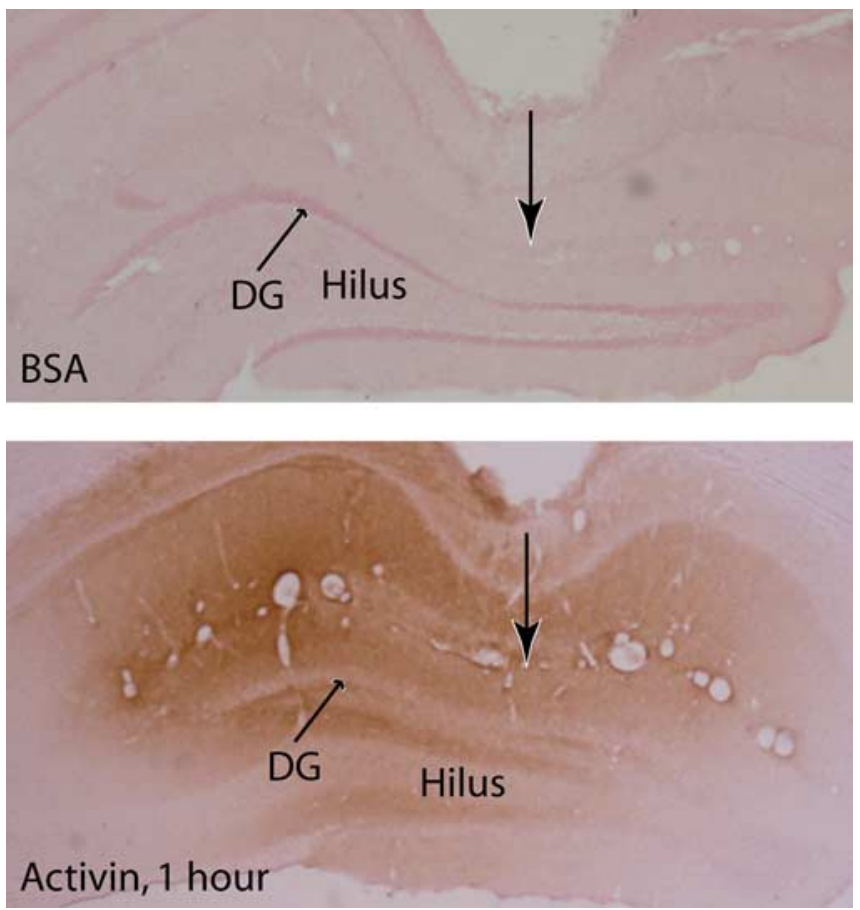

Figure 8. Activin A immunohistochemistry after local infusion into the hippocampus. Activin A $(1.0 \mu \mathrm{g})$ was infused into the dentate gyrus (DG), and activin A immunolabeling was determined $1 \mathrm{~h}$ after infusion. Representative sections are shown. Large arrows indicate the site of infusion.

\section{Analysis of activin A immunoreactivity}

Immunohistochemical analysis was performed to determine the extent of activin A diffusion and length of time exogenous activin A remains at the site of infusion. Infusions of activin A $(1.0 \mu \mathrm{g})$ into the dentate gyrus resulted in immunolabeling in the hippocampus, including areas of the dentate gyrus, molecular layer, hilus, and CA1 subfields (Fig. 8). High levels of activin A immunolabeling were observed $1 \mathrm{~h}$ after infusion. There was very little immunolabeling $3 \mathrm{~h}$ after activin infusions, and by $24 \mathrm{~h}$, when behavioral testing was conducted, there was no evidence of activin A immunolabeling (data not shown). This suggests that either very low, undectable levels of activin immunoreactivity are responsible for the behavioral effects or that activin infusions lead to adaptations that are longer-lasting than activin alone.

\section{Discussion}

The results of the present study confirm a previous report that acute ECS increases the expression of activin $\beta \mathrm{A}$ in the rat hippocampus (Andreasson and Worley, 1995) as well as in the frontal cortex. In addition, we found that there is a sustained upregulation of activin $\beta \mathrm{A}$ with chronic ECS treatment. In the hippocampus, the chronic induction of activin $\beta A$ (approximately fourfold) was reduced compared with acute ECS (approximately sevenfold), suggesting a negative feedback regulation or desensitization of the response in this region. Although the acute induction of activin $\beta \mathrm{A}$ is not consistent with the time course for the therapeutic action of ECS, rapid induction of other factors thought to be involved in the effects of ECS, such as BDNF, have also been reported (Nibuya et al., 1995, 1996). This discrepancy could be because of a time lag required for sufficient and sustained upregulation of protein levels and for the neurotrophic/ neuroprotective effects of activin to take effect.

The coinduction of activin and BDNF, and possibly other factors, could enhance the neuroprotective effect of any single factor. Activin A has been shown to be essential for the neuroprotective effect of basic fibroblast growth factor after kainic acid lesioning (Tretter et al., 2000), and activin $\beta$ A mRNA has a similar pattern of expression to BDNF mRNA after kindling in the amygdala and cortex (Foster et al., 2004). Not only is the expression pattern similar, but activin $\beta \mathrm{A}$ mRNA is colocalized to the same cells that express BDNF (Foster et al., 2004), suggesting that both contribute to a neuroprotective effect in a kainate-induced kindling model (Kelly and McIntyre, 1994). Additional studies examining the localization of activin $\beta A$ mRNA in relation to BDNF mRNA after ECS are necessary to understand the role each plays in ECS treatment.

In contrast to activin, relatively little is known about the regulation of Smads, which could underlie the neuroprotective effects of activin (Docagne et al., 2002). Another major finding of the current study is that levels of pSmad, but not total Smad, immunoreactivity are increased by acute and chronic ECS and by chronic administration of chemical antidepressants. Acute upregulation of $\mathrm{pSmad} 2$ was delayed relative to the induction of activin $\beta$ A, possibly because of a requirement for increased levels of activin $\beta A$ protein. The pattern of $\mathrm{pSmad} 2$ regulation in the hippocampus was similar to activin $\beta$ A (i.e., induction was lower in the hippocampus, after chronic treatment, approximately eightfold vs approximately fivefold). In the frontal cortex, levels of pSmad 2 were increased to a greater extent after chronic ECS treatment (approximately threefold vs approximately fivefold for acute and chronic, respectively). The greater induction of pS$\operatorname{mad} 2$ in the frontal cortex is consistent with the therapeutic time course of ECS. It is also possible that the induction of pSmad2 is more long lasting after chronic ECS, in both the hippocampus and frontal cortex, although additional studies are needed to test this hypothesis.

Upregulation of pSmad 2 in the frontal cortex by blockade of either 5-HT (fluoxetine) or norepinephrine (desipramine) reuptake, as well as ECS, suggests that pSmad2 is a common downstream target of different classes of antidepressants. The mechanisms underlying the regulation of $\mathrm{pSmad} 2$ by fluoxetine and 
desipramine are not clear because these drugs did not influence levels of activin $\beta$ A. It is possible levels of activin B protein are increased or that other factors, such as TGF- $\beta$, could contribute to the effects of chemical antidepressants. In preliminary studies, we found that ECS increased levels of TGF- $\beta$ (data not shown), which could also contribute to the actions of this treatment. However, there are also differences between activin and TGF- $\beta$, including different patterns of expression and different functions (Klempt et al., 1992; Lai et al., 1996). Further investigation is required to determine what contributions TGF- $\beta$ and activin A play in pSmad2 induction after ECS or chemical antidepressant treatment. Finally, the greater induction of pSmad 2 and upregulation of activin by ECS relative to chemical antidepressants is also consistent with the greater therapeutic efficacy of ECS treatment.

ECS produces numerous neurochemical and molecular changes in the brain, all of which may not contribute to the therapeutic efficacy of the treatment. To determine whether the ECSinduced increase in activin $\beta \mathrm{A}$ mRNA has a functional role in antidepressant treatment, the influence activin A infusions have on behavior in the FST was determined. The FST is a behavioral paradigm that is sensitive to antidepressant treatment and is used for drug discovery. Activin A infusions into the dentate gyrus granule cell layer of the hippocampus resulted in a dosedependent and region-specific (dentate gyrus but not CA1) response similar to the behavioral response of rats given fluoxetine (decreased immobility and increased swimming). Both 0.5 and $1.0 \mu \mathrm{g}$ of activin A resulted in an antidepressant-like response, and the larger dose resulted in a greater effect. The regional specificity could be attributable to differential expression of activin receptors. A functional activin receptor complex is composed of both type I (Alk4) and type II (ActRII) subtypes (Pangas, and Woodruff, 2000). Although Alk4 mRNA appears relatively high in all hippocampal subfields (Morita et al., 1996), ActRII expression is much higher in the dentate gyrus than in CA1 (Cameron et al., 1994; Bengtsson et al., 1995), and this could account for the lack of response in this subregion of the hippocampus.

Not only was there regional specificity of this response, but there was also specificity with regard to the isoform of activin. Activin B infusions into the dentate gyrus resulted in an antidepressant-like response similar to activin A infusions, including both decreased immobility and increased swimming, but infusions of inhibin A had no effect. Activin B binds to the same receptor complex as activin A (Pangas and Woodruff, 2000), so it is not surprising that infusions of activin $B$ also produce a behavioral response. In contrast, inhibin A infusions did not result in an antidepressant-like response in rats, which suggests that the behavior is specific to activin. However, we did find that coinfusions of inhibin A block the antidepressant effect of activin A. These data are consistent with the antagonist properties of inhibin, either as a competitive receptor antagonist of activin (Mathews, 1994; Pangas and Woodruff, 2000) or via an independent binding site (Draper et al., 1998; Hertan et al., 1999). These data are also consistent with the report that infusions of activin A, but not inhibin, protect hippocampal neurons from hypoxicischemic damage (Wu et al., 1999). Our results indicate that in the rat dentate gyrus, inhibin acts as an antagonist of activin with no additional effects. Activin A infusions had no effect on locomotor activity, indicating that the increase in swimming was not caused by a general increase in activity, but rather the effects of activin are a result of specific effects on FST behavior.

The activin mRNA and Smad2 phosphorylation data in conjunction with the FST data indicate that activin may play a role in the antidepressant effects of ECS. The FST data demonstrate that activin is capable of mimicking the effects of antidepressant treatment and may be a novel target for medication development. The role activin plays in neuroprotection and neural plasticity could contribute to the mechanisms underlying the actions of ECS and possibly chemical antidepressants. A leading hypothesis is that depression is associated with a loss of neural plasticity and neurotrophic support and that antidepressant treatment increases neurotrophic factor expression and reverses these effects (Duman et al., 1999; Manji and Duman 2001; Duman, 2004). It is possible that ECS-induced activin expression could protect or rescue neurons that have undergone atrophy or that are vulnerable as a result of stress or other insults. Additional studies examining the role of activin in neuronal survival and antidepressant treatment are key to answering this question.

\section{References}

Andreasson K, Worley PF (1995) Induction of $\beta$-A activin expression by synaptic activity and during neocortical development. Neuroscience 69:781-796.

Bengtsson H, Soderstrom S, Ebendal T (1995) Expression of activin receptors type I and II only partially overlaps in the nervous system. NeuroReport 7:113-116

Bottner M, Krieglstein K, Unsicker K (2000) The transforming growth factor- $\beta$ s: structure, signaling, and roles in nervous system development and functions. J Neurochem 75:2227-2240.

Cameron VA, Nishimura E, Mathews LS, Lewis KA, Sawchenko PE, Vale WW (1994) Hybridization histochemical localization of activin receptor subtypes in rat brain, pituitary, ovary, and testis. Endocrinology 134:799-808.

Detke MJ, Rickels M, Lucki I (1995) Active behaviors in the rat forced swimming test differentially produced by serotonergic and noradrenergic antidepressants. Psychopharmacology 121:66-72.

Docagne F, Nicole O, Gabriel C, Fernandez-Montreal M, Lesne S, Ali C, Plawinski L, Carmeliet P, MacKenzie ET, Buisson A, Vivien D (2002) Smad3-dependent induction of plasminogen activator inhibitor-1 in astrocytes mediates neuroprotective activity of transforming growth factor- $\beta 1$ against NMDA-induced necrosis. Mol Cell Neurosci 21:634-644.

Draper LB, Matzuk MM, Roberts VJ, Cox E (1998) Identification of an inhibin receptor in gonadal tumors from inhibin alpha-subunit knockout mice. J Biol Chem 273:398-403.

Duman RS (2004) Role of neurotrophic factors in the etiology and treatment of mood disorders. Neuromol Med 5:11-25.

Duman RS, Heninger GR, Nestler EJ (1997) A molecular and cellular theory of depression. Arch Gen Psychiatry 54:597-606.

Duman RS, Malberg J, Thome J (1999) Neural plasticity to stress and antidepressant treatment. Biol Psychiatry 46:1181-1189.

Duman RS, Malberg J, Nakagawa S, D’Sa C (2000) Neuronal plasticity and survival in mood disorders. Biol Psychiatry 48:732-739.

Duman RS, Nakagawa S, Malberg J (2001) Regulation of adult neurogenesis by antidepressant treatment. Neuropsychopharmacology 25:836-844.

Foster JA, Puchowicz MJ, McIntyre DC, Herkenham M (2004) Activin mRNA induced during amygdala kindling shows a spatiotemporal progression that tracks the spread of seizures. J Comp Neurol 476:91-102.

Hertan R, Farnworth PG, Fitzsimmons KL, Robertson DM (1999) Identification of high affinity binding sites for inhibin on ovine pituitary cells in culture. Endocrinology 140:6-12.

Inokuchi K, Kato A, Hiraia K, Hishinuma F, Inoue M, Ozawa F (1996) Increase in activin $\beta A$ mRNA in rat hippocampus during long-term potentiation. FEBS Letters 382:48-52.

Itoh S, Itoh F, Goumans MJ, ten Dijke P (2000) Signaling of transforming growth factor- $\beta$ family members through Smad proteins. Eur J Biochem 267:6954-6967.

Iwahori Y, Saito H, Torii K, Nishiyama N (1997) Activin exerts a neurotrophic effect on cultured hippocampal neurons. Brain Res 760:52-58.

Kelly ME, McIntyre DC (1994) Hippocampal kindling protects several structures from the neuronal damage resulting from kainic acid-induced status epilepticus. Brain Res 634:245-256.

Kessler RC, McGonagle KA, Zhao S, Nelson CB, Hughes M, Eshleman S, 
Wittchen HU, Kendler KS (1994) Lifetime and 12-month prevalence of DSM-III-R psychiatric disorders in the United States. Results from the National Comorbidity Survey. Arch Gen Psychiatry 51:8-19.

Klempt ND, Sirimanne E, Gunn AJ, Klempt M, Singh K, Williams C, Gluckman PD (1992) Hypoxia-ischemia induces transforming growth factor $\beta 1 \mathrm{mRNA}$ in the infant rat brain. Mol Brain Res 13:93-101.

Kodama M, Russell DS, Duman RS (2005) Electroconvulsive seizures increase the expression of MAP kinase phosphatases in limbic regions of rat brain. Neuropsychopharmacology 30:360-371.

Krieglstein K, Surter-Crazzolara C, Fischer WH, Unsicker K (1995) TGF- $\beta$ superfamily members promote survival of midbrain dopaminergic neurons and protect them against MPP ${ }^{+}$toxicity. EMBO J 14:736-742.

Lai M, Sirimanne E, Williams CE, Gluckman PD (1996) Sequential patterns of inhibin subunit gene expression following hypoxic-ischemic injury in the rat brain. Neuroscience 70:1013-1024.

Lowry OH, Rosebrough NJ, Farr AL, Randall RJ (1951) Protein measurement with the Folin phenol reagent. J Biol Chem 193:265-275.

Lucki I (1997) The forced swim test as a model for core and component behavioral effects of antidepressant drugs. Behav Pharmacol 8:523-532.

Mague SD, Pliakas AM, Todtenkopf MS, Tomasiewicz HC, Zhang Y, Stevens Jr WC, Jones RM, Portoghese PS, Carlezon Jr WA (2003) Antidepressant-like effects of kappa-opioid receptor antagonists in the forced swim test in rats. J Pharmacol Exp Ther 305:323-330.

Manji HK, Duman RS (2001) Impairments of neuroplasticity and cellular resilience in severe mood disorders: implications for the development of novel therapeutics. Psychopharmacol Bull 35:5-49.

Manji HK, Drevets WC, Charney DS (2001) The cellular neurobiology of depression. Nat Med 7:541-547.

Mathews LS (1994) Activin receptors and cellular signaling by the receptor serine kinase family. Endocr Rev 15:310-325.

Morita N, Takumi T, Hiroshi K (1996) Distinct localizaiton of two serinethreonine kinase receptors for activin and TGF- $\beta$ in the rat brain and down-regulation of type I activin receptor during peripheral nerve regeneration. Mol Brain Res 42:263-271.

Nestler EJ, Barrot M, DiLeone RJ, Eisch AJ, Gold SJ, Monteggia LM (2002) Neurobiology of depression. Neuron 34:13-25.

Nibuya M, Morinobu S, Duman RS (1995) Regulation of BDNF and trkB mRNA in rat brain by chronic electroconvulsive seizure and antidepressant drug treatments. J Neurosci 15:7539-7547.

Nibuya M, Nestler EJ, Duman RS (1996) Chronic antidepressant administration increases the expression of cAMP response element binding protein (CREB) in rat hippocampus. J Neurosci 16:2365-2372.

Pangas SA, Woodruff TK (2000) Activin signal transduction pathways. Trends Endocrinol Metab 11:309-314.

Paxinos G, Watson GC (1998) The rat brain in stereotaxic coordinates, Ed 4 San Diego: Academic.

Porsolt R, Le Pichon M, Jalfre M (1977) Depression: a new animal model sensitive to antidepressant treatments. Nature 266:730-732.

Schubert D, Kimura H, LaCorbiere M, Vaughan J, Karr D, Fischer WH (1990) Activin is a nerve cell survival molecule. Nature 344:868-870.

Taylor JR, Horger BA (1999) Enhanced responding for conditioned reward produced by intra-accumbens amphetamine is potentiated after cocaine sensitization. Psychopharmacology 142:31-40.

Tretter YP, Munz B, Hübner G, ten Bruggencate G, Werner S, Alzheimer C (1996) Strong induction of activin expression after hippocampal lesion. NeuroReport 7:1819-1823.

Tretter YP, Hertel M, Munz B, ten Bruggencate G, Werner S, Alzheimer C (2000) Induction of activin A is essential for the neuroprotective action of basic fibroblast growth factor in vivo. Nat Med 6:812-815.

Trudeau VL, Theodosis DT, Poulain DA (1997) Activin facilitates neuronal development in the rat amygdala. Neurosci Lett 237:33-36.

Wu DD, Lai M, Hughes PE, Sirimanne E, Gluckman PD, Williams CE (1999) Expression of the activin axis and neuronal rescue effects of recombinant activin A following hypoxic-ischemic brain injury in the infant rat. Brain Res 835:369-378. 